\title{
Rhabdomyoma with pericardial effusion in a new bornRequiring emergency pericardiocentisis - A Case report.
}

\author{
Siddarth S Joshi ${ }^{1}$ \\ ${ }^{I}$ Assistant professor Department of paediatrics \\ VIMS Bellary
}

\begin{abstract}
Cardiac tumours are rare in neonates, most are benign hamartomas (rhabdomyomas) of the muscle cells. Due to large size, they may cause homodynamic instability and even death in neonatal period. They are rarely diagnosed prenatally and are found in multiple forms. We report a neonate 1st of the twin, who was found to have a rhabdomyoma attached to right ventricle free valve measuring $3 \times 2.6 \mathrm{cms}$ seen compressing right ventricle, with significant pericardial effusion soon after birth with poor perfusion requiring inotropic support and emergency pericardiocentisis, following which child's condition stabilised.
\end{abstract}

\section{Case report}

A neonate, 1st of the twin born via LSCS at 34 weeks of gestation with a birth weight of $2.02 \mathrm{Kgs}$. Antenasal USG at 31 weeks had shown Rhabdomyoma in Right ventricular (RV) free wall. Baby was delivered via normal vaginal delivery, baby cried immediately after birth, APGAR at 1 min and 5 minutes was 9 and 10 respectively. At $2 \mathrm{n}$ half hours of life, on examination child's capillary refilling time was prolonged and child was started on ionotropes. ECHO was done, which showed Rhabdomyoma arising from RV free wall measuring $3 \times 2.6 \mathrm{cms}$ compressing right ventricle with large pericardial effusion measuring $1 \mathrm{cms}$ posteriorly. The effusion was partly tapped by needle pericardiocentesis, following which child's condition stabilized and there was no increase in effusion Gradually inotropes were tapered and stopped.

\section{Discussion}

Primary tumors of the heart are rare in infancy and childhood and are most often benign1. Clinical manifestations depend primarily on the location of the tumor and, to a lesser extent, on the histologic type 1 . Most common benign cardiac tumors in children are Rhabdomyomas(40-60\%)2, Fibromas(12-16\%)2, and Myxomas (2-6\%)2 . They often remain clinically unimportant and regress with age. Rarely they May cause mechanical obstruction, heart failure3, pericardial effusion or arrhythmias. Incessant ventricular tachycardia in a child younger than 2 yr should raise suspicion of a small endocardial or epicardialrhabdomyoma or Purkinje cell tumor. Treatment of rhabdomyomas4 depends on their location and size, i.e...Small asymptomatic tumors in the myocardial wall or ventricular septum may be observed for growth or regression. Rhabdomyomas associated with tuberous sclerosis often resolve as the child grows older. Large tumors that show signs of obstructing blood flow and those producing ventricular arrhythmias should be removed.

\section{References}

[1] Nadas AS, Ellison RC. Cardiac tumours in infancy. Am J Cardiol 1968; 21: 363-6

[2] 2. Beghetti M, Gow RM, Haney 1, Mawson J, Williams WG, Freedom RM: Pediatric primary benign cardiac tumours: a 15 year review. Am Heart J 1997, 134: 1107 - 1114

[3] Daniel Bernstein. Tumors of the heart. In: Kliegman, Stanton B.F, St Geme J.W, SchorN.F,Behrman R.E, Nelson textbook of pediatrics, 19e: Saunders, 2008; page 1975

[4] Butany et al., 2005. Butany J, Nair V, Naseemuddin A, et al: Cardiac tumours: Diagnosis and anagement. Lancet 2005; 6:219-228 